\title{
Risk of Catecholamine Crisis in Patients Undergoing Resection of Unsuspected Pheochromocytoma
}

\author{
Gina Song, Bonnie N. Joe, Benjamin M. Yeh, Maxwell V. Meng, Antonio C. Westphalen, Fergus \\ V. Coakley
}

Departments of Radiology (GS, BNJ, BMY, ACW, FVC) and Urology (MVM), University of California San Francisco, San Francisco, California, USA

\begin{abstract}
Purpose: To report the risk of catecholamine crisis in patients undergoing resection of unsuspected pheochromocytoma. Materials and Methods: Over a four-year period, we retrospectively identified four patients who underwent resection of adrenal pheochromocytoma in whom the diagnosis was unsuspected based on preoperative clinical, biochemical, and imaging evaluation.

Results: None of the patients exhibited preoperative clinical features of catecholamine excess. Preoperative biochemical screening in two patients was normal. CT scan performed in all patients demonstrated a nonspecific enhancing adrenal mass. During surgical resection of the adrenal mass, hemodynamic instability was observed in two of four patients, and one of these two patients also suffered a myocardial infarct.

Conclusion: Both surgeons and radiologists should maintain a high index of suspicion for pheochromocytoma, as the tumor can be asymptomatic, biochemically negative, and have nonspecific imaging features. Resection of such unsuspected pheochromocytomas carries a substantial risk of intraoperative hemodynamic instability.
\end{abstract}

Key words: adrenal gland neoplasms; imaging; surgery; pheochromocytoma; catecholamines Int Braz J Urol. 2011; 37: 35-41

\section{INTRODUCTION}

While there is widespread awareness of the classical clinical and radiological features of pheochromocytoma, it is perhaps less well known that $10 \%$ of pheochromocytomas are not associated with symptoms of excess catecholamine production, and up to $35 \%$ of pheochromocytomas have atypical imaging findings (1-5). Accordingly, the diagnosis may be unsuspected, and an indeterminate adrenal or retroperitoneal mass that is actually a pheochromocytoma could undergo resection without preoperative commencement of biochemical blockade. Such a patient is then at risk for a potentially a life-threatening intraoperative catecholamine crisis. However, while the risks of iodinated contrast administration and percutaneous biopsy have been reported in these unsuspected pheochromocytomas (6-8), to our knowledge, the risk of surgery in this population has not been well described. We recently encountered several patients who underwent surgical resection of unsuspected pheochromocytomas. Therefore, we undertook this study to report the risk of catecholamine crisis in patients undergoing resection of unsuspected pheochromocytoma.

\section{MATERIALS AND METHODS}

This was a retrospective study approved by our Committee on Human Research with waiver of 
the requirement for informed consent. Four cases of pathologically proven pheochromocytoma that underwent attempted surgical resection were identified by the study authors between 2004 and 2007. All available imaging studies and medical records of these patients were reviewed by the principal investigator. Preoperative imaging consisted of CT scan examination obtained with multiple contiguous axial images performed in the venous phase following intravenous contrast agent in all four patients with additional delayed phases obtained in two patients. One of the patients also underwent whole body PET scan after the administration of 16.4 milliCurie intravenous fluoro-2-deoxy-D-glucose (FDG) and utilizing attenuation-corrected regional emission images. None of the patients underwent imaging with iodine-131-meta-iodobenzylguanidine. The diagnosis of pheochromocytoma was confirmed by pathology of the surgically resected specimen in all four patients.

Table 1 -Clinical, imaging, and operative characteristics of four patients undergoing resection of an unsuspected pheochromocytoma.

\begin{tabular}{|c|c|c|c|c|c|c|}
\hline & $\begin{array}{l}\text { Age } \\
\text { (yrs) }\end{array}$ & Sex & $\begin{array}{c}\text { Indication for } \\
\text { CT }\end{array}$ & $\begin{array}{l}\text { Laboratory } \\
\text { Studies }\end{array}$ & $\begin{array}{c}\text { Imaging } \\
\text { Modality/Findings }\end{array}$ & $\begin{array}{c}\text { Intraoperative/ } \\
\text { Postoperative Course }\end{array}$ \\
\hline 1 & 76 & $\mathrm{~F}$ & $\begin{array}{l}\text { Staging of cecal } \\
\text { tubulovillous } \\
\text { adenoma. }\end{array}$ & $\begin{array}{c}\text { Normal } 24 \\
\text { hour urinary } \\
\text { vanillyl-man- } \\
\text { delic acid and } \\
\text { normetaneph- } \\
\text { rine. }\end{array}$ & $\begin{array}{l}\text { CT scan with intravenous } \\
\text { contrast agent, venous and } \\
\text { delayed phases. Homoge- } \\
\text { neously enhancing } 1.3 \mathrm{x} \\
1.7 \mathrm{~cm} \text { right adrenal mass, } \\
<50 \% \text { washout on delayed } \\
\text { images ( } 141 \mathrm{HU} \text { to } 87 \mathrm{HU} \text { ). }\end{array}$ & $\begin{array}{l}\text { Open right hemicolectomy } \\
\text { and adrenalectomy. Intraop- } \\
\text { erative blood pressure rise } \\
\text { to } 200 / 100 \mathrm{~mm} \text { Hg followed } \\
\text { by drop to } 70 / 30 \mathrm{~mm} \text { Hg on } \\
\text { administration of antihyper- } \\
\text { tensives. Transient ventricu- } \\
\text { lar ectopy with bigeminy. } \\
\text { Postoperative troponin and } \\
\text { EKG changes of non Q- } \\
\text { wave myocardial infarction. }\end{array}$ \\
\hline 2 & 64 & $\mathrm{~F}$ & $\begin{array}{l}\text { Abdominal } \\
\text { pain. }\end{array}$ & None. & $\begin{array}{l}\text { CT scan with intravenous } \\
\text { contrast agent, venous } \\
\text { phase. Heterogeneously } \\
\text { enhancing } 4.0 \text { x } 4.5 \mathrm{~cm} \\
\text { retroperitoneal mass arising } \\
\text { from the left adrenal gland. }\end{array}$ & $\begin{array}{l}\text { Open exploratory laparoto- } \\
\text { my and adrenalectomy. In- } \\
\text { traoperative blood pressure } \\
\text { rise to } 220 / 110 . \text { Normoten- } \\
\text { sive following expeditious } \\
\text { removal of lesion. }\end{array}$ \\
\hline 3 & 49 & $\mathrm{M}$ & $\begin{array}{l}\text { Staging of } \\
\text { metastatic } \\
\text { melanoma. }\end{array}$ & None. & $\begin{array}{l}\text { PET and intravenous con- } \\
\text { trast-enhanced portal venous } \\
\text { phase CT. Heterogeneously } \\
\text { enhancing } 2.8 \text { x } 2.9 \mathrm{~cm} \text { left } \\
\text { adrenal mass, SUV of } 4.8 \text {. }\end{array}$ & $\begin{array}{l}\text { Laparoscopic adrenalec- } \\
\text { tomy. Uneventful intraop- } \\
\text { erative and postoperative } \\
\text { course. }\end{array}$ \\
\hline 4 & 25 & $\mathrm{~F}$ & $\begin{array}{l}\text { Restaging of } \\
\text { Hodgkin's lym- } \\
\text { phoma previ- } \\
\text { ously treated by } \\
\text { chemotherapy } \\
\text { and radiother- } \\
\text { apy. }\end{array}$ & $\begin{array}{l}\text { Normal plasma } \\
\text { metanephrine } \\
\text { and normeta- } \\
\text { nephrine. }\end{array}$ & $\begin{array}{l}\text { CT scan with noncontrast, } \\
\text { intravenous contrast-en- } \\
\text { hanced portal venous, and } \\
\text { delayed phases. Homoge- } \\
\text { neously enhancing } 2.2 \mathrm{x} \\
1.8 \mathrm{~cm} \text { right adrenal mass, } \\
<50 \% \text { washout on delayed } \\
\text { images ( } 130 \mathrm{HU} \text { to } 107 \mathrm{HU} \text { ). }\end{array}$ & $\begin{array}{l}\text { Laparoscopic adrenalec- } \\
\text { tomy. Uneventful intraop- } \\
\text { erative and postoperative } \\
\text { course. }\end{array}$ \\
\hline
\end{tabular}




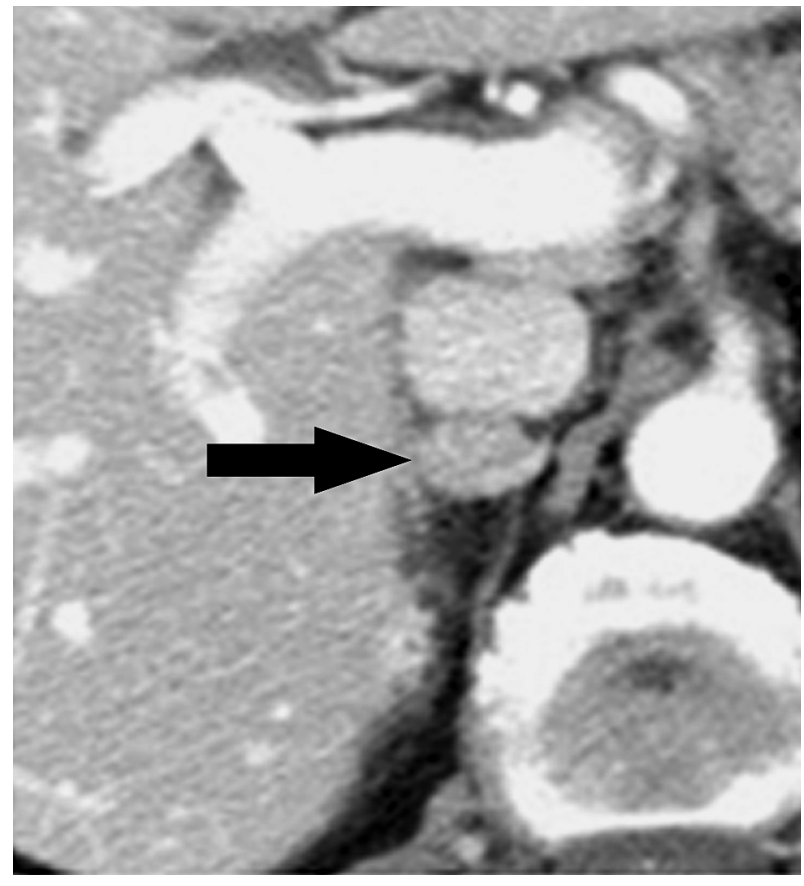

Figure 1 - Axial contrast-enhanced portal venous phase CT scan in a 76 year old woman undergoing preoperative staging of a cecal mass (Case 1 in Table-1). A homogeneously enhancing right adrenal mass (arrow) is seen, and showed less than 50\% washout on delayed images (not shown). The patient proceeded to right hemicolectomy and adrenalectomy, because the working diagnosis before surgery was of possible adrenal metastasis. Surgery was complicated by hemodynamic instability and a postoperative non- $Q$ wave myocardial infarction. Final pathology revealed a cecal tubulovillous adenoma and an adrenal pheochromocytoma.

\section{RESULTS}

The clinical and radiologic characteristics and intraoperative and postoperative course of the four patients in this study are summarized in Table1. Three of the patients underwent imaging for purposes of staging a malignancy, and one patient underwent imaging for abdominal pain. None of the four patients exhibited preoperative clinical features of catecholamine excess. One patient underwent serologic analysis, which demonstrated normal levels of plasma metanephrine and normetanephrine. Another patient underwent urinary analysis, which demonstrated normal levels of urinary vanillylmandelic acid and normetanephrine. All patients demonstrated an adrenal mass (mean diameter 2.7 $\mathrm{cm}$, range 1.7 to $4.5 \mathrm{~cm}$ ) with associated heterogeneous $(n=2)$ or homogeneous $(n=2)$ enhancement on CT scan. Delayed images obtained in two cases demonstrated less than fifty percent washout. One patient had additional imaging with PET, which demonstrated increased FDG uptake within the lesion. The radiological findings of the four patients are highlighted in Figures-1 to 4 . All 4 patients proceeded to adrenalectomy, either open $(n=2)$ or laparoscopic $(n=2)$. The intraoperative course of two patients was notable for blood pressure lability peaking at $200 / 100$ to $220 / 110 \mathrm{mmHg}$ systolic/diastolic. The postoperative course of one of these two patients was complicated by an elevated troponin level to 9.7 and an electrocardiogram consistent with a non Q-wave myocardial infarction.

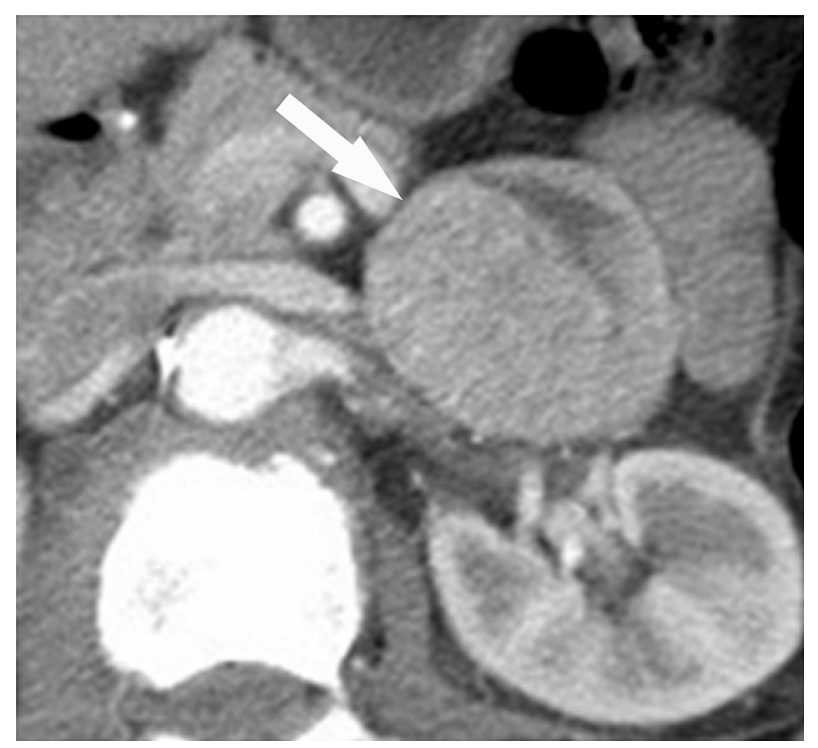

Figure 2-Axial contrast-enhanced portal venous phase CT scan in a 64 year old woman with abdominal pain (Case 2 in Table-1). A heterogeneously enhancing mass (arrow) is seen anterior to the left renal vessels. The left adrenal gland (not shown) was identified just superior to this mass. Open exploratory laparotomy and adrenalectomy was performed, based on a preoperative working diagnosis of retroperitoneal sarcoma. Surgery demonstrated a mass arising exophytically from the inferior aspect of the left adrenal gland, and was complicated by intraoperative hemodynamic instability. The mass was removed expeditiously and final pathology revealed a diagnosis of pheochromocytoma. 


\section{COMMENTS}

Our study illustrates the importance of keeping a high index of suspicion for the possibility of
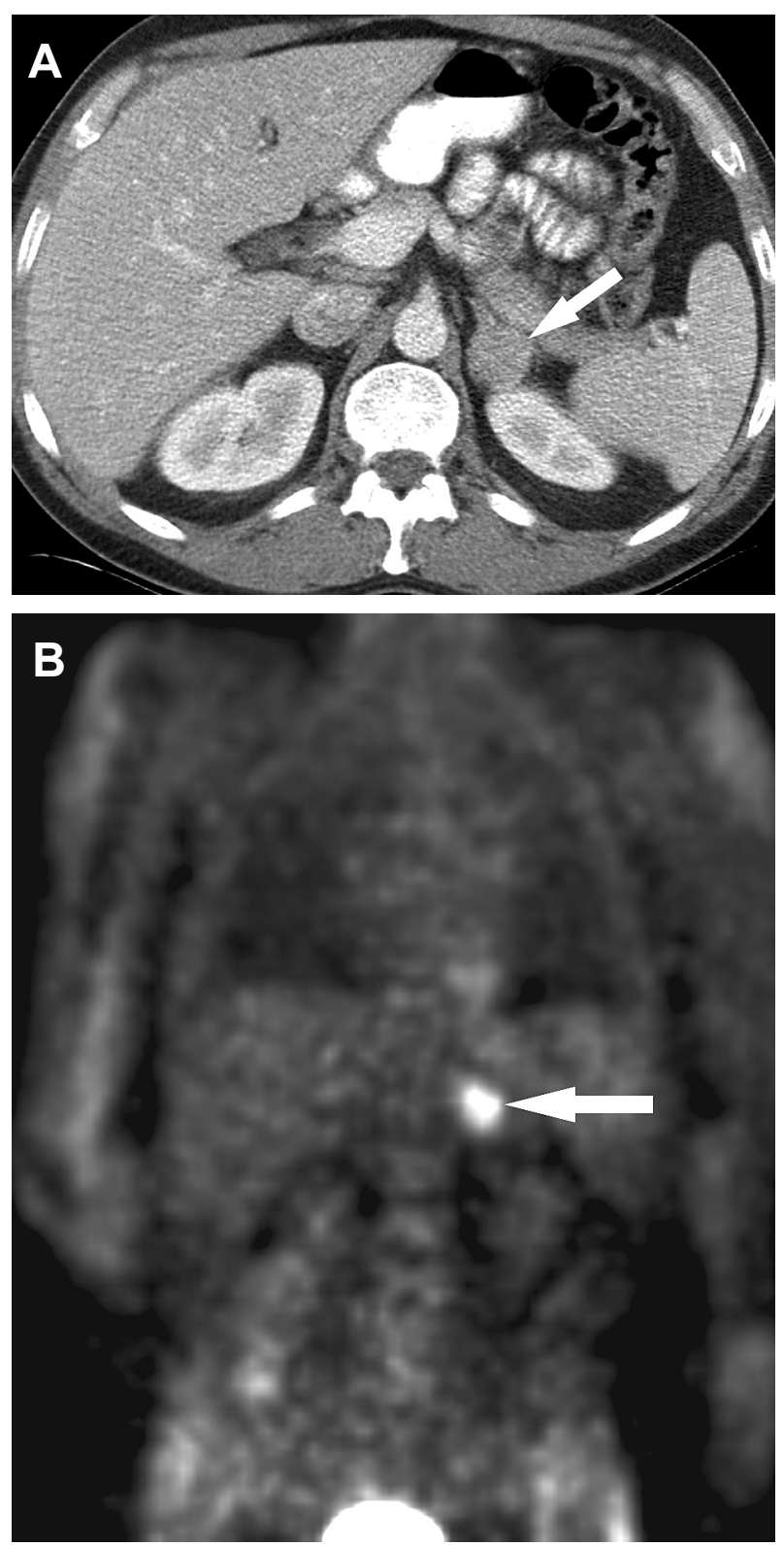

Figure 3 - A) Axial contrast-enhanced portal venous phase CT scan in a 49 year old man with melanoma (Case 3 in Table-1) shows a homogeneously enhancing left adrenal mass (arrow). B) Coronal PET image shows increased fluoro-2-deoxy-D-glucose (FDG) uptake in the mass (arrow). The patient proceeded to laparoscopic adrenalectomy for presumed metastatic disease, with an uneventful intraoperative and postoperative course. Final pathology revealed a diagnosis of pheochromocytoma. pheochromocytoma for any retroperitoneal mass. While hemodynamic instability associated with surgical and laparoscopic resection of known or suspected pheochromocytoma has been reported $(9,10)$, the risk of resection in the population of unsuspected pheochromocytoma has not been well described to our knowledge. Two out of four of our patients demonstrated intraoperative hemodynamic instability that may have been prevented by appropriate preoperative alpha-blockade. The postoperative morbidity in our population might also have been averted, as the myocardial infarction of one of our patients was presumably related to the sudden intraoperative hypertensive challenge.

Defining typical characteristics of a pheochromocytoma by $\mathrm{CT}$ is difficult as heterogeneous enhancement and poor washout as well as FDG uptake on PET may also be seen in a metastasis or adenoma $(1,4,11)$. Further imaging by magnetic resonance (MR) is also problematic, as up to $35 \%$ of pheochromocytomas do not exhibit the "lightbulb bright" high T2 signal classically associated with pheochromocytomas (1). Current guidelines on preoperative diagno-

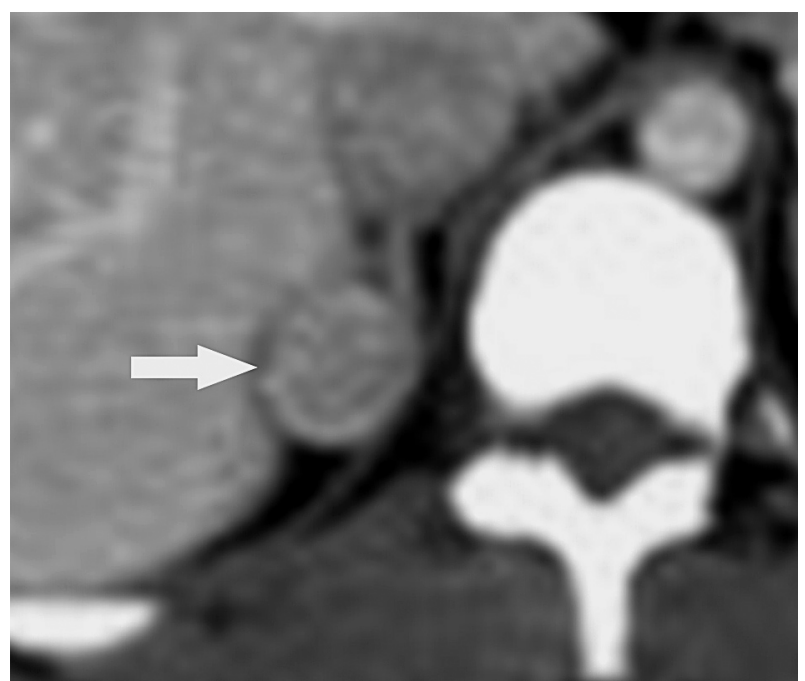

Figure 4 - Axial contrast-enhanced portal venous phase CT scan in a 25 year old woman undergoing re-staging of Hodgkin's lymphoma previously treated by chemotherapy and radiotherapy (Case 4 in Table-1) shows a homogeneously enhancing right adrenal mass (arrow). The patient proceeded to laparoscopic adrenalectomy for suspected recurrent lymphoma, with an uneventful intraoperative and postoperative course. Final pathology revealed a diagnosis of pheochromocytoma. 
sis thus include additional studies after diagnosis of an adrenal mass with nonspecific characteristics on cross-sectional imaging. Metaiodobenzylguanidine (MIBG) reportedly has an excellent specificity of up to $100 \%$ and may increase the sensitivity of pheochromocytoma detection to around $80 \%(10,12)$. Given the suboptimal sensitivity of biochemical markers alone, a combination of MIBG imaging supplemented with biochemical testing is currently recommended $(12,13)$. Such an imaging approach may result in better preoperative identification of pheochromocytomas, and facilitate commencement of pre-operative alpha blockade. Both appropriate pretreatment with alpha blockade and readily available intraoperative antihypertensive agents have been shown to decrease intraoperative lability (14). While pretreatment does not exclude the possibility of intraoperative fluctuations in blood pressure $(9,10)$, more favorable blood pressure control may be achieved with a combination of pretreatment and intraoperative medications (15). In a recent series of 24 patients who underwent laparoscopic adrenalectomy for adrenal pheochromocytoma (most were treated pre-operatively with prazosin), no cases of intra-operative hemodynamic instability were reported (16). While such pharmacological blockade may prevent clinically significant hemodynamic changes, it may not prevent biochemical changes. For example, analysis of serial catecholamine levels in 11 patients undergoing 12 laparoscopic adrenalectomies while being maintained on an intravenous alpha 1 blocker showed significant elevations related to the induction of pneumoperitoneum and manipulation of the adrenal gland (17).

Our report has several limitations. The study is a small retrospective case series, and cases were not identified systematically. Patients with enhancing adrenal masses with poor washout or increased FDG uptake at PET imaging undergoing resection were not studied prospectively, and as such, the frequency of pheochromocytoma in adrenal masses with nonspecific imaging characteristics is unknown. Only two out of four patients received screening for catecholamines, and systematic evaluation of the rate of false negatives either by urinary or plasma analysis was therefore not made. Further imaging with MIBG was not obtained in any of our patients, and the rate of false negatives by MIBG was thus not obtained.
In conclusion, we report that two of four patients who underwent resection of unsuspected pheochromocytoma sustained intraoperative hemodynamic instability. This study emphasizes the asymptomatic presentation, nonspecific imaging characteristics, potential for false negative preoperative laboratory analysis, and resultant risk of catecholamine crisis in patients with adrenal masses. Accordingly, both surgeons and radiologists should maintain a high index of suspicion for pheochromocytoma before resection of nonspecific adrenal masses even in asymptomatic patients. Further studies to better delineate the imaging and biochemical preoperative evaluation of these patients are required.

\section{CONFLICT OF INTEREST}

None declared.

\section{REFERENCES}

1. Blake MA, Kalra MK, Maher MM, Sahani DV, Sweeney AT, Mueller PR, et al.: Pheochromocytoma: an imaging chameleon. Radiographics. 2004; 24 (Suppl 1): S87-99.

2. Mayo-Smith WW, Boland GW, Noto RB, Lee MJ: State-of-the-art adrenal imaging. Radiographics. 2001; 21: 995-1012.

3. Sutton MG, Sheps SG, Lie JT: Prevalence of clinically unsuspected pheochromocytoma. Review of a 50-year autopsy series. Mayo Clin Proc. 1981; 56: 354-60.

4. Dunnick NR, Korobkin M: Imaging of adrenal incidentalomas: current status. AJR Am J Roentgenol. 2002; 179: 559-68.

5. Mansmann G, Lau J, Balk E, Rothberg M, Miyachi Y, Bornstein SR: The clinically inapparent adrenal mass: update in diagnosis and management. Endocr Rev. 2004; 25: 309-40.

6. Mukherjee JJ, Peppercorn PD, Reznek RH, Patel V, Kaltsas G, Besser M, et al.: Pheochromocytoma: effect of nonionic contrast medium in CT on circulating catecholamine levels. Radiology. 1997; 202: 227-31.

7. Bessell-Browne R, O'Malley ME: CT of pheochromocytoma and paraganglioma: risk of adverse events with i.v. administration of nonionic contrast material. AJR Am J Roentgenol. 2007; 188: 970-4. 
8. Casola G, Nicolet V, vanSonnenberg E, Withers C, Bretagnolle M, Saba RM, et al.: Unsuspected pheochromocytoma: risk of blood-pressure alterations during percutaneous adrenal biopsy. Radiology. 1986; 159: 733-5.

9. Kinney MA, Warner ME, vanHeerden JA, Horlocker TT, Young WF Jr, Schroeder DR, et al.: Perianesthetic risks and outcomes of pheochromocytoma and paraganglioma resection. Anesth Analg. 2000; 91: 111823.

10. Bravo EL, Tagle R: Pheochromocytoma: state-ofthe-art and future prospects. Endocr Rev. 2003; 24: 539-53.

11. Yoon JK, Remer EM, Herts BR: Incidental pheochromocytoma mimicking adrenal adenoma because of rapid contrast enhancement loss. AJR Am J Roentgenol. 2006; 187: 1309-11.

12. Guller U, Turek J, Eubanks S, Delong ER, Oertli D, Feldman JM: Detecting pheochromocytoma: defining the most sensitive test. Ann Surg. 2006; 243: 102-7.

13. Kudva YC, Sawka AM, Young WF Jr: Clinical review
164: The laboratory diagnosis of adrenal pheochromocytoma: the Mayo Clinic experience. J Clin Endocrinol Metab. 2003; 88: 4533-9.

14. Weismann D, Fassnacht M, Schubert B, Bonfig R, Tschammler A, Timm S, et al.: A dangerous liaison-pheochromocytoma in patients with malignant disease. Ann Surg Oncol. 2006; 13: 1696-701.

15. Chung PC, Ng YT, Hsieh JR, Yang MW, Li AH: Labetalol pretreatment reduces blood pressure instability during surgical resection of pheochromocytoma. J Formos Med Assoc. 2006; 105: 189-93.

16. Castilho LN, Simoes FA, Santos AM, Rodrigues TM, dos Santos Junior CA: Pheochromocytoma: a longterm follow-up of 24 patients undergoing laparoscopic adrenalectomy. Int Braz J Urol. 2009; 35: 24-31; discussion 32-5.

17. Rocha MF, Tauzin-Fin P, Vasconcelos PL, Ballanger $\mathrm{P}$ : Assessment of serum catecholamine concentrations in patients with pheochromocytoma undergoing videolaparoscopic adrenalectomy. Int Braz J Urol. 2005; 31: 299-307; discussion 307-8.

Accepted after revision: August 3, 2010

\section{Correspondence address:}

Dr. Fergus Coakley

Chief, Abdominal Imaging

University of California San Francisco

Box 0628, M-372, 505 Parnassus Avenue

San Francisco, CA 94143-0628, USA

E-mail: fergus.coakley@radiology.ucsf.edu

\section{EDITORIAL COMMENT}

The authors of this paper deserve to be complimented because, despite the modest data, that was analyzed retrospectively, they raise some issues that are very relevant for those who study and treat adrenal diseases.

First of all, they point out that adrenal masses, and I would add retroperitoneal masses in general, can be pheochromocytomas or paragangliomas without clinical signs or with very subtle symptoms, which do not lead the physician to consider lesions that produce adrenergic substances. In my personal experience (13 ), I had the opportunity to find some pheochromocytomas that had not been diagnosed preoperatively, much like the authors of this paper. Even worse, I found pheochromocytomas that had been diagnosed by endocrinologists as non-functioning, which produced adrenergic discharges in the operating room, causing all of the risks described by the authors. 
Secondly, the authors show that any surgeon is likely to encounter a patient that has not been properly diagnosed and reacts to what he believes to be a pheochromocytoma in the beginning of the procedure, causing hemodynamic instability. This creates a dilemma to the surgical team: move forward or abort the procedure? In my personal opinion, the safest measure is to stop the procedure and adequately prepare the patient for another surgery 30 or 45 days later. However, I acknowledge that if the team is very experienced (both surgeons and anesthesiologists), in a hospital with all the necessary resources (medications and support), the procedure can be carried out with good chances of success.

Finally, and this is the main point of my analysis before the facts that were presented by the authors, each case of adrenal mass or retroperitoneal mass suspected of being a pheochromocytoma or a paraganglioma, regardless of the existence of symptoms, must be exhaustively analyzed by an endocrinologist with expertise in adrenal diseases. Personally, I do not consider myself capable of making such evaluation and I believe that most adrenal surgeons are not. From my own personal experience, I believe that most endocrinologists are not capable of performing this task.

\section{REFERENCES}

1. Castilho LN: Laparoscopic adrenalectomy--experience of 10 years. Arq Bras Endocrinol Metabol. 2004; 48: 77683.

2. Castilho LN, Simoes FA, Santos AM, Rodrigues TM, dos Santos Junior CA: Pheochromocytoma: a long-term followup of 24 patients undergoing laparoscopic adrenalectomy. Int Braz J Urol. 2009; 35: 24-31; discussion 32-5.

3. Castilho LN, Castillo OA, Dénes FT, Mitre AI, Arap S: Laparoscopic adrenal surgery in children. J Urol. 2002; 168: 221-4.

\section{Dr. Lísias Nogueira Castilho Section of Urology Catholic University Campinas Campinas, SP, Brazil E-mail: lisias@dglnet.com.br}

